\title{
La ley francesa 98.389 del 19 de mayo de 1998 de responsabilidad por el hecho de productos defectuosos. Sus fuentes principales
}

\author{
Luis O. Andorno*
}

\section{INTRODUCCIÓN}

La especial circunstancia de haberse dictado en Francia la ley $n^{\circ}$. 98-389 del 19 de mayo de 1998 referida a la responsabilidad por el hecho de los productos defectuosos, nos ha llevado a considerar conveniente efectuar un comentario comparativo de la misma con las soluciones de la Convención del Consejo de Europa de 1977 relativa a la responsabilidad por el hecho de productos en caso de lesiones corporales o de deceso y de la Directiva del Consejo de las Comunidades Europeas del 25 de julio de 1985.

Ello así por cuanto entre estos tres instrumentos legales existen numerosos aspectos comunes cuyo análisis conducirá a una mejor comprensión acerca de la letra y el espíritu de la referida ley del 19 de mayo de 1998.

Mas aún. Puede decirse que esta ley $\mathrm{n}^{\circ} .389$ del 19 de mayo de 1998 procura aplicar en Francia la referida Directiva del 25 de julio de 1985, según autorizadas opiniones vertidas en dicho país ( Henri, Léon et Jean Mazeaud et Francois Chabas, Lecons de Droit Civil. T. II, vol. I, Obligations. Théorie générale, 9e. édition por Francois Chabas, Montchrestien, Paris, 1998, $\left.n^{\circ} .381\right)$. De allí por tanto el interés especial que representa el análisis de aquella normativa.

Todo ello, como se verá luego, se halla orientado a brindar una adecuada protección al consumidor o usuario al facilitar el resarcimiento por los daños que pudiere sufrir en su persona o

\footnotetext{
" Professor de Direito Constitucional da Universidade Nacional de Rosário, Argentina.
} 
bienes. La idea básica - además de otras circunstancias - consiste en prescindir de lo que en tiempo pasado fue un elemento fundamental para la atribución de responsabilidad cual es " la culpa" para reemplazarla por un concepto "objetivo".

En nuestro anunciado propósito de análisis comparativo de los referidos regímenes legales vamos a considerar distintos aspectos vinculados con esta cuestión.

\section{LA RESPONSABILIDAD DEL PRODUCTOR}

$\mathrm{Y}$ así tenemos en primer lugar que el artículo 1386-1 del Código Civil francés, incorporado por la ley $\mathrm{n}^{\circ} .98$ 389 del 19 de mayo de 1998 reza: "El productor es responsable del daño causado por un defecto de su producto, esté o no ligado por un contrato con la víctima".

Podemos encontrar un antecedente de dicho precepto en el artìculo $3^{\circ}$, inc. $1^{\circ}$. de la mencionada "Convención Europea sobre la responsabilidad por el hecho de los productos en caso de lesiones corporales o de deceso" de 1977, Llamada Convención de Estrasburgo, que dice:"El productor está obligado a reparar los daños resultantes de un deceso o de lesiones corporales causadas por un defecto de su producto".

También la Directiva de 1985 dispone en su art. $l^{\circ}$. que el productor es responsable por el daño causado " por un defecto de su producto".
Refiriéndose a este precepto señala Yván Markovits en su libro : "La Directiva de la C.E.E. del 25 de julio de 1985 sobre la responsabilidad por el hecho de los productos defectuosos" que dicha Directiva contempla en realidad una responsabilidad por el hecho de los productos defectuosos y no por el hecho del productor, lo cual es muy importante a los fines de determinar la responabilidad consiguiente (op.cit., Paris, 1990, p. 162 y ss.).

Ello es muy interesante a los fines del presente comentario comparativo que estamos efectuando, pues tanto en la Convención de Estrasburgo de 1977, cuanto en la Directiva de 1985, cuando en el texto del referido artículo 1386-1 del Código Civil francés, agregado por la ley $\mathrm{n}^{\circ}$. 98-389 de 1998, se consigna de modo expreso que el productor es responsable por el daño causado por un defecto "de su producto".

Por lo demás, la responsabilidad en cabeza del productor no surgirá del daño causado por cualquier producto, sino de un producto "defectuoso", cuyo alcance determinaremos más adelante.

Resulta asimismo de interés poner de resalto que este nuevo precepto del Código Civil francés, trae como novedad el hecho de que el productor será responsable por el daño causado por un defecto de su producto "esté o no ligado por un contrato con la víctima". Ello amplía notoriamente el campo de aplicación de dicho precepto, al no requerir necesariamente la existencia de un vínculo contractual entre el responsable y la vìctima. Ello 
contribuirá sin dudas a aventar algunas dificultades que se presentaron en el pasado respecto de esta cuestión.

\section{DAÑOS A LOS BIENES O A \\ LA PERSONA}

El nuevo artículo 1386-2 del Código Civil francés, agregado por dicha ley 98-389, prescribe que: "Las disposiciones del presente título se aplican a la reparación del daño que resulte de un ataque a la persona o a un bien distinto que el propio producto defectuoso".

En cambio, la Convención de Estrasburgo de 1977, tenía un alcance más limitado toda vez que: "el productor está obligado a reparar los daños resultantes de un deceso o de lesiones corporales causadas por un defecto de su producto". Aquí no figuran los daños resultantes a los bienes, sino solamente los perjuicios resultantes de un deceso o de lesiones corporales.

Por su parte, conforme al artículo 9 de la Directiva de 1985, en forma coincidente con el nuevo precepto del Código Civil, transcripto precedentemente, la responsabilidad surge por el daño causado por la muerte o por lesiones corporales, como asimismo por el daño causado a una cosa, distinta naturalmente al mismo producto.

Para los daños causados a las cosas la responsabilidad no tiene límites, aun cuando se aclara que no están cubiertos sino los daños causados a las cosas "de un tipo normalmente destinado al consumo o al uso privados".
Por lo demás, la Directiva de 1985 solamente comprende los daños patrimoniales, estando por ende excluido el daño moral, en el caso de muerte o lesiones corporales. No obstante, la misma deja a salvo las disposiciones nacionales relativas a los "daños inmateriales". Y en este sentido, en Francia, la legislación nacional protectora del consumidor y del usuario, ha ampliado la noción de daño también al perjuicio moral resultante de la muerte o de lesiones corporales. El texto de dicho artículo 1386-2 del Código Civil permite una interpretación amplia en este sentido, toda vez que el mismo recoge pacífica doctrina autoral $y$ jurisprudencial y textos legales anteriores, en el sentido de que son resarcibles tanto los daños patrimoniales cuanto los extrapatriomiales causados por el uso o consumo de productos defectuosos.

\section{CONCEPTO DE PRODUCTO}

El artículo 1386-3 del Código Civil francés, agregado por la ley 98-389, reza: "Es un producto todo bien mueble, aun cuando esté incorporado en un inmueble, comprendiendo asimismo los productos del suelo, de la ganadería, de la caza y de la pesca. La electricidad es considerada como un producto".

De su lado, el artículo $2^{\circ}$, inciso a) de la Convención Europea de 1977, consigna que "el término "producto" designa todo mueble, natural o industrial, sea el mismo bruto o manufacturado, aun cuando esté 
incorporado a otro mueble o a un inmueble", en tanto que la Directiva de 1985, consigna en su artículo $2^{\circ}$ que: "A los efectos de la presente Directiva se entiende por producto cualquier bien mueble, excepto las materias primas agrícolas y los productos de la caza, aun cuando esté incorporado a otro bien mueble o a un inmueble". Además, conforme a dicha Directiva, se entiende por ""materias primas agrícolas"”'a los productos de la tierra, de la ganadería y de la pesca, exceptuando aquellos productos que hayan sufrido una transformación inicial.Por producto se entiende también la electricidad".

De un simple cotejo entre algunos de los distintos textos transcriptos precedentemente, aparece neta la superioridad del concepto de producto plasmado en la redacción del referido art. 1386-3 del Código Civil francés, como resultante de una evolución experimentada en este campo, hacia una ampliación del concepto de "producto".

Así mientras en la Directiva de 1985 se excluyen de modo expreso a las materias primas agrícolas y a los productos de la caza, que no hubieran experimentado una primera transformación; en dicho artículo 1386-3 del Código Civil, se hallan incluidos explìcitamente "los productos del suelo, de la ganadería, de la caza y de la pesca". Se trata de un razonable ensanchamiento del concepto de "producto" que indudablemente repercutirá favorablemente en el propósito del legislador de proteger cada vez más adecuadamente a los consumidores y usuarios por los daños que pudieren sufrir en su persona o bienes.

Resulta asimismo importante poner de resalto que si bien la Convención de Estrasburgo no incluye dentro de la caracterización del "producto " a la electricidad, sí en cambio lo hacen, tanto la Directiva de 1985, cuanto el referido artículo 1386-3 del Código Civil. Ello coincide con el articulo 2311 del Código Civil argentino, luego de la redacción sustitutiva dispuesta por la ley 17711 en cuanto prescribe que "las disposiciones referentes a las cosas son aplicables a la energía y a las fuerzas naturales susceptibles de apropiación". Resulta también de interés destacar que la doctrina y jurisprudencia francesas han considerado que también pueden ser incluìdos en la categoría de "productos", en un plano similar al de la electricidad, tanto al gas como a los productos radioactivos.

Añádase que el art. 14 de la Directiva de 1985 excluye de su ámbito de aplicación a los daños resultantes "de accidentes nucleares que son cubiertos por convenciones internacionales ratificadas por los Estados miembros".

En síntesis, pues, conforme al referido art. 1386-3 del Código Civil, se considera producto a todo bien mueble, aun cuando estuviere incorporado a un inmueble, comprendiéndose asimismo los productos del suelo, de la ganadería, de la caza y de la pesca, como así también la electricidad. 
Tanto en dicho Código Civil francés, cuanto en la Directiva de 1985, se excluyen de modo implícito los inmuebles, pues no están mencionados en las respectivas definciones de "producto".

Ello ha sido criticado, pues los inmuebles habían sido incluidos en la primera propuesta de Directiva Europea presentada en 1976. La razón de la exclusión de los inmuebles en la Directiva de 1985, parece haberse debido a la existencia de regulaciones particulares en todos los Estados miembros de la entonces Comunidad Europea (hoy Unión Europea) acerca de los vicios de la construcción.

Cabe recordar en el presente comentario que el art. $2^{\circ}$, párrafo $1^{\circ} \mathrm{del}$ Código de Protección y Defensa del Consumidor del Brasil (ley n ${ }^{\circ} .8078 \mathrm{del}$ 11 de setiembre de 1990), vigente a partir de 1991, prescribe: "Producto es cualquier bien, mueble o inmueble, material o inmaterial". Creemos sería el criterio adecuado.

\section{PRODUCTO DEFECTUOSO}

Conforme a lo consignado en los párrafos precedentes resulta importante caracterizar al producto defectuoso.

En este sentido, el art. 1386-4 del Código Civil francés, agregado por la ley 98-389, prescribe: "Un producto es defectuoso en el sentido del presente título cuando no ofrece la seguridad a la que se puede legítimamente esperar. En la apreciación de la seguridad a la que se puede legítimamente esperar, deben tenerse en cuenta todas las circunstancias y principalmente la presentación del producto, el uso que puede razonablemente esperarse y el momento de su puesta en circulación.

Un producto no puede ser considerado como defectuoso por el solo hecho de que otro, más perfeccionado, haya sido posteriormente puesto en circulación".

El mismo reproduce en forma prácticamente textual el art. $6^{\circ}$. de la Directiva de 1985, que a su vez tiene como antecedente el art. $2^{\circ}$., inc. c, de la Convención de Estrasburgo de 1977, que dice: "el producto presenta un 'defecto' cuando no ofrece la seguridad que se puede legítimamente esperar, teniendo en cuenta todas las circunstancias, comprendida entre ellas, la presentación del producto".

A fin de mejor aprehender el concepto de producto defectuoso, nos parece importante reproducir la fundamentación que sobre el punto es dable advertir en la Directiva de 1985. Allí se sostuvo que "para proteger la integridad física y los bienes del consumidor, la determinación del carácter defectuoso de un producto debe hacerse no en función de la inaptitud del producto para el uso, sino en función del defecto de seguridad a la cual el gran público puede legítimamente esperar; la cual seguridad se apreciará además excluyendo todo uso abusivo del producto o de modo irracional en el caso concreto" (Journal officiel des Communautés européennes, num. L 210/29, 7/8/1985). 
Como lo señalamos oportunamente en nuestro trabajo: Responsabilidad por los productos defectuosos (La Directiva del Consejo de las Comunidades Europeas vista desde la Repúbllica Argentina), La Ley, 1986-E,doctrina, ps.948/49, pensamos que la mencionada definición legal de "defecto" en cuanto "ausencia de seguridad a la cual puede legítimamente esperarse", recogida en los distintos instrumentos legales analizados precedentemente, resulta adecuada, no obstante algunas críticas que se han formulado a la misma para el supuesto de desconocerse la causa del perjuicio o bien para la hipótesis de daños causados por un producto no defectuoso en razón de sus características peligrosas.

Cabe recordar que la jurista española Parra Lucan expresa que el concepto de "defecto" era ajeno a la normativa continental de responsabilidad civil. Sin embargo, la referida Directiva de 1985, siguiendo el criterio estadounidense adopta la categoría de "defecto" como noción esencial del sistema de responsabilidad civil. De este modo, conforme a la Directiva, el productor no será responsable de cualquier daño ocasionado en el uso o consumo de un producto, sino únicamente de los que tengan su origen en un defecto del mismo. En este sentido, la doctrina norteamericana ha puesto de relieve cómo la necesidad de que un producto sea defectuoso para que su fabricante sea responsable de los daños ocasionados en su uso o consumo responde a la idea de que, suprimida la exigencia de culpa como presupuesto de la responsabilidad, es preciso adoptar un límite, de tal manera que no se responda por la simple puesta en circulación de un producto. Algo parecido ha sido por tanto lo ocurrido en la elaboración del art. $6^{\circ}$. de la referida Directiva comunitaria europea (M.A. Parra Lucan, Daños por productos y protección del consumidor, Barcelona, 1990, p. 497).

Cabe señalar asimismo que un concepto similar en el punto ha plasmado en el art. $5^{\circ}$ de la ley argentina de Defensa del Consumidor y del Usuario No. 24240 vigente a partir de 1993, que dice: "Las cosas y servicios deben ser suministrados o prestados en forma tal que, utilizados en condiciones previsibles o normales de uso, no presenten peligro alguno para la salud o integridad física de los consumidores o usuarios".

El artículo habla de utilización en condiciones privisibles o normales del producto o servicio. Se ha señalado que para determinar dichos extremos resulta de fundamental importancia tener presente el público al cual cada producto o servicio va dirigido, pues en determinados casos la información y presentación puede llegar a requerir condiciones específicas. Así, por ejemplo, en los productos o servicios destinados a los llamados subconsumidores, es decir, aquellas personas que por diversas razones están en una situación de debilidad mayor que el común de la gente (v.gr.:los niños, ancianos, analfabetos o personas poco 
instruìdas, extranjeros, etc. (Roberto A. Vázquez Ferreyra y Oscar E. Romera, Protección y defensa del consumidor, Ley 24.240, Depalma, Bs. As., 1994, p. 26).

Por lo demás, dicho art. $5^{\circ}$ de la ley 24.240 armoniza con los arts. $4^{\circ}$. y $6^{\circ}$. de dicha ley en cuanto procuran una adecuada protección para la salud y seguridad de los consumidores y usuarios contra los riesgos derivados de los denominados accidentes del consumo. Brevitatis causa, remitimos a nuestro trabajo: "Responsabilidad por daño a la salud o la seguridad del consumidor", publicado en el libro: "La responsabilidad" en homenaje al Profesor Dr. Isidoro H. Goldenberg, dirigido por los Dres. Atilio Aníbal Alterini y Roberto M. López Cabana, Abeledo Perrot, Bs. As., 1995, p.479).

Resulta asimismo de interés poner de resalto que tanto en la Convención de Estrasburgo de 1977, cuanto en la Directiva de 1985, como así en el referido art. 1386-4 del Código Civil francés, exigen que a los fines de apreciar la existencia de un defecto en el producto deben apreciarse distintas circunstancias.

Entre ellas, naturalmente la presentación del producto, es decir, su etiquetaje, su embalaje, el envase, las instrucciones para su utilización, etc.

Se hace referencia asimismo al uso que razonablemente puede esperarse del producto en cuestión. De este modo, si el consumidor o usuario efectuar un uso del producto inadecuado o inesperado, forzoso será concluir que el daño no podrá atribuirse a un defecto del producto.

También deberá tomarse en cuenta el momento de la puesta en circulación del producto-problema del que nos ocuparemos más adelante-habida cuenta que el máximo de rendimiento y seguridad que puede razonablemente esperarse del producto lo será justamente al momento de su puesta en circulación, pudiendo aquellos factores ser menores luego de algún tiempo de uso del mismo.

Volviendo al referido art. 1386-4 del Código Civil francés, cabe señalar que el mismo dispone en su parte final que un producto no podrá ser considerado como defectuoso por el solo hecho de que otro, más perfeccionado, ha sido puesto en circulación con posterioridad.

Ello significa por tanto que se permite a los fabricantes exonerarse de los daños derivados del denominado riesgo del desarrollo.

En efecto, con la expresión riesgo del desarrollo se hace referencia al riesgo de daños como consecuencia del insuficiente desarrollo de la ciencia o de la técnica en el momento en que el producto ha sido puesto en circulación.

De este modo, los llamados riesgos del desarrollo suponen el carácter defectuoso de un producto del que, sin embargo, no se conocía ni se podía conocer la potencialidad dañosa. Esto es de aplicación, por ejemplo, en materia de productos farmacéuticos, cuya morbosidad suele ser descubierta mucho tiempo después de habérselos puesto en el comercio (Atilio Aníbal 
Alterini, Oscar Jose Ameal y Roberto M. López Cabana, Derecho de Obligaciones Civiles y Comerciales, Abeledo-Perrot, Bs. As., 1995, p. 808).

Ahora bien, se ha recordado que el problema de tales riesgos del desarrollo fue en el proceso de elaboración de la referida Directiva de 1985, uno de los puntos que más discusiones produjo, poniendo de relieve de manera evidente la contraposición de intereses entre los consumidores y los productores.

Frente a ello, esta Directiva, adoptó en el punto, una solución de compromiso, permitiendo a los distintos Estados miembros apartarse de la regla de responder por los daños derivados del mencionado riesgo del desarrollo (Parra Lucan, op.cit., p. 519 y ss.).

Y como acaba de verse, el mencionado artículo 1386-4 del Código Civil francés, agregado por la ley $98 /$ 386 , siguiendo una tradicional corriente de doctrina autoral y jurisprudencial de dicho país, adoptó el criterio de no responsabilizar al fabricante por los daños derivados del riesgo del desarrollo.Añádase que en el derecho alemán impera un criterio contrario, toda vez que se hace responsable al fabricante por los daños derivados de dicho riesgo del desarrollo.Lo mismo ocurre en Luxemburgo y Finlandia.

Debe decirse asimismo que en el Proyecto de Código Unico argentino de 1987 (hoy ley vetada) se propició descartar la puesta en cabeza del productor de tales riesgos del desarrollo (art. 1113, in fine). El mismo criterio fue seguido por el Proyecto del Poder
Ejecutivo de 1993, al propiciar que : "El elaborador responde por los daños causados por el defecto del producto por él fabricado", pero "podrá liberarse probando las siguientes circunstancias:........ $4^{\circ}$.) Los conocimientos científicos y técnicos no permitían suponer la existencia del defecto al momento de la puesta en circulación del producto".

En cambio, en las Jornadas Marplatenses de Responsabilidad Civil y Seguros, realizadas en Mar del Plata en el año 1989, se sostuvo un criterio contrario, al recomendar poner a cargo del productor tales riesgos, en su carácter de garante de la inocuidad de los bienes lanzados al mercado.

\section{LA PUESTA EN \\ CIRCULACIÓN DEL PRODUCTO}

El art. 1386-5, incluido también en el Código Civil francés por la ley del 19 de mayo de 1998, dice: "Un producto es puesto en circulación cuando el productor se ha desprendido voluntariamente del mismo.Un producto no puede ser objeto sino de una sola puesta en circulación".

En forma más o menos similar, el art. $2^{\circ}$., inciso d) de la Convención de Estrasburgo 1977, habìa propiciado a su turno la siguiente fórmula: "un producto ha sido "puesto en circulación" cuando el productor lo ha remitido a otra persona".

Por su parte, el art. $7^{\circ}$. a) de la Directiva de 1985 señala que el productor no será responsable "cuando 
no ha puesto en circulación el producto defectuoso".

Un análisis comparativo de estos distintos instrumentos legales, permite diferentes conclusiones.

Así, en primer lugar, parece natural sostener que ninguna responsabilidad tendrá el productor que no hubiera puesto el producto defectuoso en circulación, es decir, cuando no lo hubiera lanzado al mercado, esto es, al circuito de distribución.

En segundo lugar, por el contrario, deberá considerarse que un producto ha sido puesto en circulación cuando el productor se ha desprendido voluntariamente del mismo, como por ejemplo, en el caso en que ha perdido su poder de mando o de control sobre el mismo, por transportarse un producto no terminado aun sobre la vía pública, a fin de que se complete el proceso de su fabricación.

También, cuando ha vendido o transferido el producto por cualquier causa a otra persona.

En tercer lugar, de lo expuesto se desprende, como bien lo consigna el referido art. 1386-5 del Código Civil francés, que un producto solamente podrá ser objeto de "una sola puesta en circulación".

Pero, comentando este precepto, los hermanos Mazeaud y Chabas, señalan que aquí se presenta una dificultad para los productos compuestos, a propósito de lo cual hay que remitirse asimismo a los arts. 1386-3, art. 1396-11, último párrafo y art. 13868, del Código Civil francés, a cuyos respectivos comentarios remitimos en el presente trabajo. Pero aclaran que dicha definición del referido art. 13865 , tiene la ventaja de excluir la hipótesis del robo o del objeto confiado a un dependiente.

La referida dificultad se presente, según dichos distinguidos juristas, en el caso de un automóvil que ha sido el causante de un accidente por cuanto uno de sus neumáticos, que tenía un defecto, reventó. Este neumático fue fabricado por la empresa $A$ y vendido al fabricante del automóvil B, en una fecha $\mathrm{x}$. B pone en circulación el automóvil nuevo en una fecha y. Si se considera que el neumático permanece siendo el mismo producto, todo el mundo será liberado a partir de $\mathrm{x}$ más diez años. Pero si se considera que el neumático se ha transformado en un nuevo producto, $B$ no será liberado sino a partir de y más diez años. Pero frente a los terceros, A¿quedará liberado a partir de la fecha $x$ más diez años? Se nos responde que conforme al art. 13868 del Código Civil, los dos fabricantes son solidariamente responsables. Es exacto. Pero ello no impide que el primer fabricante A se ha "desprendido voluntariamente", esto es, ha puesto el ciruculaciòn la pieza con fecha $x$. Además, la lectura del art. 1386-3-a cuyo comentario remitimos-nos conduce a pensar que el producto incorporado permanece siendo "el" producto. ¿Habrá que concluir que A y $B$ no incurrirán en responsabilidad a fecha $x$ más diez años? Así, a mérito de las primeras ( $\mathrm{y}$ únicas) puestas en 
circulación de las piezas, el plazo de diez años variará para un mismo producto compuesto? (Mazeaud y Chabas, op.cit., Paris, 1998, No. 558-2, nota 5). Dificultad esta última que deberá solucionar la jurisprudencia en base a los distintos textos legales involucrados.

\section{CARACTERIZACIÓN DEL PRODUCTOR}

Parece obvio destacar la importancia que tiene el productor $y$ sus asimilados, en el ámbito de la responsabilidad por productos elaborados que estamos considerando.

En este sentido, el artículo 1386-6 del Código Civil francés, agregado por la reforma de 1998, dice: "Es productor, cuando actúa a título profesional, el fabricante de un producto terminado, el productor de una materia prima, el fabricante de una parte componente del producto".

Está asimilado a un productor para la aplicación del presente título toda persona que actúa a título profesional:

$\left.1^{\circ}\right)$ Que se presenta como productor colocando sobre el producto su nombre, su marca $\mathrm{u}$ otro signo distintivo.

$2^{\circ}$ ) Que importa un producto en la Comunidad Europea en vista de una venta, de una locación, con o sin promesa de venta, o de toda otra forma de distribución.

No son considerados productores, en el sentido del presente título, las personas cuya responsabilidad puede ser atribuida con fundamento en los arts. 1792 y $1646-1 "$.

De su lado, el art. 2, inc. b) de la Convención de Estrasburgo de 1977, con un alcance más reducido señala que "el término "productor" designa a los fabricantes de productos terminados o de partes componentes y a los productores de productos naturales".

Por su parte, el art. $3^{\circ}$. de la Directiva de 1985, guarda similitud con el referido art. 1386-6 del Código Civil, al considerar como productor al fabricante del producto, al que se presenta como productor en razón de colocar sobre el producto, su nombre, su marca u otro signo distintivo. También se asimila al productor, el imporador comunitario del producto $y$ eventualmente a todo proveedor en la cadena de distribución.

Por ser dicho precepto del Código Civil el más claro y completo nos ha parecido conveniente glosar el mismo.

Así se tiene en primer lugar que será considerado productor aquel que actuar " a título profesional", es decir, con conocimientos o aptitudes especiales en la materia, frente al "consumidor o usuario" que son considerados la parte débil de la relación de consumo y que merecen por tanto la protección del ordenamiento jurídico (cf. Aída Kemelmajer de Carlucci,La responsabilidad colectiva y los daños producidos por los productos elaborados, Revista Jurídica de San Isidro, t. 24, p. 135; Gabriel A. Stiglitz, Efectos relativos de los contratos y responsabilidad del fabricante, L.L. 
1986-C-2, Atilio A. Alterini, La reponsabilidad civil por productos: estado de la cuestión en el derecho argentino, L.L. 1989-E-1178).

De esta manera, será así productor el fabricante real de un producto terminado. En la misma categoría será productor el que lo sea de una "materia prima", como así el que lo sea de " una parte componente" del producto.

Luego se tienen otros protagonistas que de acuerdo a dicho precepto son "asimilados" al productor.

En este sentido se tiene por ejemplo a aquel que presentarse como productor "colocando sobre el producto su nombre, su marca u otro signo distintivo". Es lo que cierto sector de la doctrina francesa ha denominado productor "putativo", en razón de aparecer como colocando sobre el producto su nombre, su marca u otro signo distintivo, aun cuando no haya sido el fabricante del producto.

También el referido artículo 13866 , ha asimilado al produdor, en cuanto a su responsabilidad por los daños emergentes del producto defectuoso, al que hubiera importado un producto en la Comunidad Europea "en vista de una venta, de una locación, con o sin promesa de venta, o de toda otra forma de distribución".

Con ello se quiere procurar el máximo de garantías al consumidor o usuario por los daños que pudiere haber sufrido en su persona o bienes. En efecto, a través de la responsabilidad del importador se procura facilitar el acceso a la justicia de aquellos damnificados por productos fabricados en otro país.

También se establece la responsabilidad de los proveedores en este artículo, que a diferencia de la Directiva de 1985, ya no es subsidiaria (para el caso de no indicar la identidad del productor, del eventual importador o proveedor del producto, en un plazo razonable), sino que se halla ubicado en un plano de igualdad con los otros responsables.

Los hermanos Mazeaud y Chabas, manifiestan que tanto las personas mencionadas en dicho art. 1386-5 del Código Civil, cuanto las mencionadas en el artículo siguiente, del que nos ocuparemos inmediatamente, serán probablemente consideradas responsables in solidum frente a la víctima . Creemos se trata de un criterio razonable.

En cuanto al párrafo final del art. 1386-6, transcripto precedentemente, piensan se trata del caso de los constructores y de los vendedores de inmuebles a construirse que tienen un régimen especial de responsabilidad frente al damnificado (Mazeaud y Chabas, op.cit., Paris, 1998, No ${ }^{\circ}$ 558-3).

Para completar el presente comentario queremos recordar que el art. 40 de la ley argentina de Defensa del Consumidory del Usuario $\mathrm{N}^{\circ} .24240$, en la redacción dada por la ley 24.999 , promulgada el 24 de julio de 1998,que puso adecuado remedio al injusto veto del P.E. a dicho precepto y que mereciera la crítica generalizada de nuestra doctrina y jurisprudencia, dice: 
" Si el daño al consumidor resulta del vicio o riesgo de la cosa o de la prestación del servicio, responderán el productor, el fabricante, el importador, el distribuidor, el proveedor, el vendedor y quien haya puesto su marca en la cosa o servicio. El transportista responderá por los daños ocasionados a la cosa con motivo o en ocasión del servicio. La responsabilidad es solidaria, sin perjuicio de las acciones de repetición que correspondan. Sólo se liberará total o parcialmente quien demuestra que la causa del daño le ha sido ajena". Más adelante volveremos sobre este precepto.

\section{OTROS RESPONSABLES ASIMILADOS AL PRODUCTOR}

Sin lugar a dudas un articulo novedos lo es el 1386-7 del Código Civil francés, pues no tiene precedentes ni en la Convención de Estrasburgo de 1977 ni en la Directiva de 1985. El mismo recoge precedentes de la doctrina autoral y jurisprudencial, al prescribrir que: "El vendedor, el locador, con excepción del otorgante de un leasing o del locador asimilable a dicho otorgante de un leasing, o todo otro proveedor profesional es responsable del defecto de seguridad del producto en las mismas condiciones que el productor.

El recurso del proveedor contra el productor obedece a las mismas reglas que la demanda promovida por la víctima directa del defecto. No obstante, debe accionar dentro del año siguiente a la fecha de su citación ante la justicia".

Si se compara este precepto con la Convención de Estrasburgo de 1977 y con la Directiva de 1985, puede decirse que se trata de una norma original, pues los responsables mencionados en el mismo - excepción hecha del proveedor en la cadena de distribución referido en dicha Directiva, solamente responsable para el supuesto de que el productor o el importador no fueren identificados por dicho proveedor en un plazo razonable - no figuran en tales instrumentos legales.

De esta manera, según dicho artículo 1386-7 del Código Civil francés, el vendedor (con excepción del otorgante de un leasing o del locador asimilable a éste) o todo otro proveedor profesional es responsable del defecto de seguridad en las mismas condiciones que el productor.

Opinan los Mazeaud y Chabas que las mencionadas personas seguramente serán consideradas responsables in solidum frente a la víctima. No obstante dicho proveedor tiene un recurso contra el productor, recurso que, según la ley, obedece a las mismas reglas que pudiere intentar la víctima directa. Señalan asimismo dichos juristas, que si el texto legal no habla de subrogación, es sin dudas por que el plazo para esta acción recursoria es aquí diferente de aquél que dispone la víctima: el solvens debe accionar dentro del año siguiente al de la fecha de su citación en justicia. Parece que la naturaleza (subrogatoria o autónoma) de esta citación en justicia 
no ha sido suficientemente precisada. (Mazeaud y Chabas, op. cit., No. 558-3).

\section{RESPONSABILIDAD SOLIDARIA}

El artículo 1386-8 del Código Civil francés, agregado por la ley 98-389, dispone que: "En caso de daño causado por el defecto de un producto incorporado en otro, el productor de la parte componente y quien ha realizado la incorporación son solidariamente responsables".

Ya hemos visto anteriormente que de acuerdo a la Convención de Estrasburgo de 1977, el termino "productor" designa a los "fabricantes de productos terminados o de partes componentes y a los productores de productos naturales".

Además, conforme al art. 3 , inc. $4^{\circ}$. de la misma, "en caso de daños causados por un defecto del producto incorporado en otro producto, el productor del producto incorporado y quien ha realizado la incorporación serán responsables".

Por su parte, la Directiva de 1985, luego de establecer también una responsabilidad tanto del productor del producto incorporado y de quien realizó dicha incorporación, prescribe que el fabricante de una "parte componente" puede exonerarse de su responsabilidad si prueba que el defecto es imputable a la concepción del producto al cual fue incorporada dicha parte o a las instrucciones dadas por el fabricante del producto (art. 7.f).
Como se desprende de lo expuesto, el referido art. 1386-8 del Código Civil francés, sin dudas, reconoce como antecedentes tanto a la referida Convención de 1977, cuanto a la Directiva de 1985.

Se establece así que en caso de daño causado por el defecto de un producto incorporado en otro, tanto el productor de dicha parte componente cuanto quien ha realizado la correspondiente incorporación, son solidariamente responsables.

Se trata de un principio razonable que procura brindar mayor protección a la víctima del daño.

Se ha señalado con acierto que en la hipótesis de dicho precepto del Código Civil, una misma cosa, esto es, el producto terminado, puede hacer nacer la responsabilidad de varios productores (Mazeaud y Chabas, op.cit., No. 558-3).

\section{PRUEBA A CARGO DEL ACTOR}

El artículo 1386-9 del Código Civil francés reza: "El actor debe probar el daño, el defecto y la relación de causalidad entre el defecto y el daño".

El mismo reconoce como antecedente inmediato el art. 4 de la Directiva de 1985 en cuanto prescribe que: "La víctima está obligada a probar el daño, el defecto y la relación de causalidad entre el defecto y el daño".

Comentando dicha directiva en nuestro trabajo: "La responsabilidad civil por los daños causados por los 
productos elaborados en el ámbito del Mercosur" en el libro en homenaje al Prof. Dr. Félix A. Trigo Represas, hemos tenido ocasión de sostener que la misma significa por tanto que la víctima no se halla obligada a acreditar la culpa del causante del daño. En la exposición de motivos de dicha directiva se dice que: "...solamente la responsabilidad sin culpa del productor" permite resolver de modo adecuado el problema,propio a nuestra época de tecnicidad creciente, de una atribución justa de los riesgos inherentes a la producción técnica moderna" (Journal officiel des Communautés européennes, núm. L 210/29, 7/8/1985) (Cf. nuestro referido trabajo publicado en L.1. 1986-E-946).

En efecto, tanto dicha Directiva cuanto el mencionado art. 1386-9 del Código Civil francés, siguiendo la tendencia general imperante en el mundo, se inclinan por un sistema de responsabilidad objetiva en materia de responsabilidad por daños derivados de productos elaborados. Volveremos luego sobre este punto. Solamente queremos significar asimismo que es el criterio adoptado por el art. 40 de la Ley de Defensa del Consumidor y del Usuario No. 24240 y modificatorias posteriores, transcripto precedentemente. En forma coincidente se tiene que el art. 12 del referido Código de Defensa del Consumidor del Brasil, vigente desde 1991, prescribe que: " $E 1$ fabricante, o productor, o constructor, nacional o extranjero, y el importador responden, independientemente de la existencia de culpa, por la reparación de los daños causados a los consumidores por defectos derivados del proyecto, fabricación, construcción, montaje, fórmulas, manipulación, presentación o acondicionamiento de sus productos, como así en razón de informaciones insuficientes o inadecuadas sobre su utilización y riesgos". En comentario a dicho precepto se ha sostenido que en el derecho brasileño, el régimen de responsabilidad del fabricante no es más el régimen común.La responsabilidad por culpa en este ámbito cede su espacio a la responsabilidad objetiva (José Reinaldo de Lima Lópes, Responsabilidade Civil do Fabricante e a Defensa do Consumidor, Biblioteca do Direito do Consumidor, Editora Revista dos Tribunais, San Pablo, Brasil, 1992, p. 145). También recordamos que en el Brasil, de acuerdo a la ley número 7347 de 1985 se ha instituido una acción pública para la defensa de diversos intereses difusos, entre los cuales deben mencionarse los relativos a la protección del medio ambiente, del patrimonio cultural y a la defensa de los derechos del consumidor, entre otros (Vasto della Giustina, Responsabilidade civil dos grupos. Inclusive no Código do Consumidor, Aide Editora, Rio de Janeiro: 1991, p. 145).

Añádase, que tal tendencia a objetivar la responsabilidad civil en materia de productos elaborados, como así a invertir la carga de la prueba a fin de defender a los consumidores o usuarios, se mantiene en líneas 
generales en las leyes específicas de protección de los consumidores vigentes en distintos países. Entre ellos, naturalmente, el nuestro, desde que el art. 40 de la ley 24.240 - transcripto precedentemente - debe considerarse incluido dentro de esta corriente.

En nuestro comentario al artículo siguiente del Código Civil francés, ampliaremos nuestro análisis sobre este tema.

\section{EXENCIÓN DE RESPONSABILIDAD EXCEPCIONES}

El artículo 1386-11 del Código Civil francés, agregado por la ley 98-389, dispone lo siguiente: "El productor es responsable de pleno derecho a menos que pruebe:

$1^{\circ}$ ) Que no haya puesto el producto en circulacion;

$2^{\circ}$ ) Que, tomando en cuenta las circunstancias, pudiere estimarse que el defecto causante del daño no existía en el momento en que el producto fue puesto en circulación por el mismo o que el defecto nació posteriormente;

$3^{\circ}$ ) Que el producto no haya sido destinado a la venta o a toda otra forma de distribución;

$4^{\circ}$ ) Que el estado de los conocimientos científicos y técnicos existentes al momento en el que fue puesto en circulación el producto, no haya permitido descubrir la existencia del defecto;

$5^{\circ}$ ) Que el defecto se haya debido a la conformidad del producto con reglas imperativas de orden legislativo o reglamentario.

El productor de la parte componente no es más responsable si establece que el derecto es imputable a la concepción del producto en el cual esta parte ha sido incorporada o a las instrucciones dadas por el productor de ese producto".

Podemos rastrear como fuente del presente artículo - entre otras - al art. $5^{\circ}$, primera parte, de la Convención de Estrasburgo de 1977, que dice: " 1 . El productor no es responsable, en los términos de la presente Convención, si prueba: a) Que el producto no había sido puesto en circulación por el mismo; o b) que tomando en consideración las circunstancias, pudiere estimarse que el defecto causante del daño no existía al momento en el que el producto fue puesto en circulación por el mismo o que ese defecto nació posteriormente; o c) que el producto no haya sido fabricado ni para la venta, la locación o toda otra forma de distribución con un propósito económico por parte del productor ni fabricado o distribuido en el ámbito de su actividad profesional."

En el comentario que efectuaremos seguidamente haremos asimismo referencia a la Directiva de 1985 , que por cierto también contempla causales de exclusión de responsabilidad similares a las expuestas.

Dicho artículo nuevo del Código Civil francés corrobora lo afirmado precedentemente en el sentido de que se ha implementado un sistema de responsabilidad objetiva o sin culpa. 
En efecto, si el productor logra acreditar alguna de las causales contempladas por el mismo se eximirá de responsabilidad. Ellas significan la existencia de una causa extraña. Ello así por cuanto se está en presencia de situaciones que implican una ruptura del nexo de causalidad y que en algunos casos tienen vinculación con el carácter defectuoso del producto e inclusive con la propia definición de producto que también hemos considerado anteriormente.

Así se tiene en primer término que de acuerdo al inciso $l^{\circ}$.) del mencionado artículo, el productor se eximirá naturalmente de responsabilidad, si probare que no "puso el producto en circulación". Ya nos hemos ocupado de este tema en nuestro comentario al art. 1386-5 de dicho cuerpo legal, por lo que nos remitimos al mismo.

Por lo demás, conforme al inciso $2^{\circ}$.), también se liberará el productor en el supuesto de que el defecto causante del daño no existiere al momento en que el producto hubiera sido puesto en circulación . Ello coincide con el art. 7.b) de la Directiva de 1985, que precisa asimismo que el juez no debe exigir una prueba absoluta, debiendo conformarse con un grado de probabilidad suficiente O bien, cuando dicho defecto hubiere nacido con posterioridad. Parece obvio que en tales casos sería injusto responsabilizar al productor.

También se exonerará de responsabilidad el productor cuando el producto no hubiera sido destinado a la venta o a toda otra forma de distribución.
En efecto, el sistema de responsabilidad establecido en los distintos cuerpos legales que estamos examinando parte del presupuesto de que el producto defectuoso estuviere destinado a la venta o a toda otra forma de distribución entre los consumidores o usuarios.

El inciso $4^{\circ}$. del artículo 1386-11 del Código Civil francés refiere a los denominados riesgos del desarrollo, tema del que también nos hemos ocupado anteriormente, en nuestro comentario al art. 1386-4, in fine, al que también nos remitimos en mérito a la brevedad. Se trata, como se ha recordado de riesgos causados por una insuficiencia del desarrollo de la ciencia o de la técnica al tiempo en que el producto hubiera sido puesto en circulación. De este modo, dicho nuevo texto, fiel a la constante tradición francesa en la materia - a diferencia de lo que ocurre en el derecho alemán, como así en el derecho de Finlandia y de Luxemburgo - pone tales riesgos a cargo de los damnificados potenciales. Ello coincide con lo preconizado por la Diretiva de 1985, que establece la posibilidad de eximición de responsabilidad por parte del productor, en una soluciòn de compromiso con el Parlamento europeo que deja librado esta cuestión a la solución que puedan adoptar cada uno de los países. En efecto, dicha Directiva de 1985, señala que el productor podrá eximirse de responsabilidad si prueba que el estado de conocimientos "científicos y técnicos al momento de la puesta en circulación 
del producto por el mismo no le haya permitido descubrir la existencia del defecto".

Podrá también eximirse de responsabilidad el productor si el defecto se hubiere debido a la conformidad del producto "con las reglas imperativas de orden legislativo o reglamentario" (art. 1386-11, inc. $5^{\circ}$.). Ello coincide con el art. 7 de la Directiva de 1985.Se trata de un supuesto en el cual el productor ha tenido que ajustarse obligatoriamente a normas legales imperativas, sin margen para apartarse de ellas. El defecto no resulta por tanto del producto en sí mismo sino de tales normas legales. Siendo ello parece justo que no podrá responsabilizarse a dicho productor. De cualquier modo, debe decirse que se trata de un supuesto de exoneración de rara aplicación en la práctica.

Finalmente, conforme a la última parte de dicho art. 1386-11, el productor de la parte componente no será responsable si establece que el defecto del producto causante del daño fuere debido a dos circunstancias:a) a la concepción del producto en el cual esta parte ha sido incorporada y b) a las instrucciones dadas por el fabricante de dicho producto.

Tal norma reconoce como antecedente inmediato art. 7.f) de la Directiva de 1985, que se reproduce en forma pràcticamente textual.

Parece justa esta disposición habida cuenta del papel protagónico que tiene el productor en la fabricación integral del producto final, esto es, en cuanto fabricante del producto y de su gestión decisiva en la incorporación de la parte componente. Obviamente, si el defecto de la parte componente reconociere como causa la concepción del producto en el cual aquella ha sido incorporada o bien las instrucciones dadas por el productor, sería injusto responsabilizar al productor de la parte componente, por cuanto no podría hablarse de defecto de esta última.

Debe destacarse no obstante que el art. 1386-12 del Código Civil francés contempla un par de excepciones a algunas de las causales de exoneración enumeradas en el artículo anterior, que acabamos de comentar.

Así se señala en primer lugar que el productor no podrá invocar la causal de exoneración prevista en el inciso $4^{\circ}$. de dicho artículo - daños derivados del denominado riesgo del desarrollo cuando el daño hubiere sido causado por un elemento del cuerpo humano o bien por productos salidos del mismo. Se trata de una excepción original, que por cierto no figuraba ni en la Convención de Estrasburgo de $1977 \mathrm{ni}$ en la Directiva de 1985. Parece natural que en los supuestos contemplados por la primera parte de dicho artículo 138612 del mencionado cuerpo legal, no sería adecuado ampararse en la referida causal de liberación de responsabilidad basada en los daños derivados del llamado riesgo del desarrollo.

Por su parte, conforme al párrafo segundo de dicho artículo 1386-12 del Código Civil francés, el productor no 
podrá invocar las causas de exoneración previstas en el mencionado inciso $4^{\circ}$. del artículo anterior - al que acabamos de referirnos - ni en el inçiso $5^{\circ}$. del artículo 1386-11, que prevé el caso del defecto del producto debido a la conformidad a reglas imperativas de orden legal o administrativo, cuando en presencia de un defecto que se hubiere revelado en un plazo de diez años luego de la puesta en circulación del producto, no hubiere adoptado las disposiciones adecuadas a prevenir las consecuencias dañosas.

Añádase que esta excepción a la regla de la exoneración de responsabilidad contemplada por este segundo párrafo del art. 1386-12, reconoce como antecedentes a la Convención de Estrasburgo de 1977 (art. 7) y a la Directiva de 1985 (art. 11).

Respecto de este último precepto de la Directiva de 1985 hemos sostenido oportunamente que en rigor de verdad nos encontramos aquí frente a un verdadero plazo de caducidad en virtud del cual la victima vería extinguido su derecho luego de transcurrido un plazo de 10 años a partir de la fecha de puesta en circulación del producto, a menos que durante ese período hubiera entablado una acción judicial.

Además, hecho señalado también que tal plazo de 10 años tendría igualmente la ventaja de facilitar los seguros y la amortización del capital. Asimismo dicho plazo de caducidad constituiría un período aceptable " toniendo en cuenta que una gran gama de productos diferentes se supone pueden durar más de 10 años (por ejemplo ciertos productos mecánicos), en tanto que otros están destinados a ser consumidos en un plazo muy breve (como por ejemplo los productos alimenticios)", según se indicó en la Exposición de Motivos de la mencionada Convención de Estrasburgo de 1977 ("Rapport explicatif concernant la Convention européenne sur la responsabilité $d u$ fait des produits en caso de lésions corporel.es et de décés", p. 20, Estrasburgo, 1977. Vide nuestro referido trabajo publicado en L.L.1986-E-947).

Pensamos así que el referido plazo de caducidad de 10 años debe reputarse aceptable, pues contempla adecuadamente los intereses de los consumidores y los de los productores, asegurando un justo equilibrio entre los mismos.

Creemos también que las razones expuestas pueden asimismo resultar de aplicación, mutatis mutandis, al segundo párrafo del presente artículo 1386-12 del Código Civil francés.

Volvercmos sobre estas cuestiones al analizar el art. 1386-16 de dicho cuerpo legal.'

\section{LIMITACIÓN O SUPRESIÓN DE LA RESPONSABILIDAD DEL PRODUCTOR}

El artículo 1386-13 del Código Civil francés, agregado por la ley $9 \&-389$ del 19 de mayo de 1998, dice: "La responsabilidad del productor puede ser 
reducida o suprimida, teniendo en cuenta todas las circunstancias, cuando el daño ha sido causado conjuntamente por un defecto del producto o por la culpa de la víctima o de otra persona por la cual la víctima debe responder".

El mismo tiene una redacción similar al artículo 4 de la Convención de Estrasburgo de 1977, como así al art. 8.2 de la Directiva de 1985.

Acerca de dicho artículo 1386-13 del Código Civil francés, podemos decir que en rigor de verdad será el juzgador quien en cada caso particular deberá decidir en función de las distintas circunstancias que rodean al mismo.

Así, en algunos casos la responsabilidad del productor podrá ser reducida o directamente suprimida, cuando el daño hubiere sido causado conjuntamente por un defecto del producto o por la culpa de la victima o de otra persona por la cual la vìctima debe responder.

En los distintos casos a decidir parece obvio decir que jugará un papel muy importante la equidad, tomando en cuenta la naturaleza del defecto del producto y la naturaleza de la culpa en que hubiere incurrido la vìctima o el tercero por quien ésta deba responder.

Se trata de un principio similar al incorporado al art. 1113 del Código Civil argentino, luego del agregado introducido por la ley 17711 en cuanto prescribe que "En los supuestos de daños causados con las cosas, el dueño o guardián, para eximirse de responabilidad, deberá demostrar que de su parte no hubo culpa; pero si el daño hubiere sido causado por el riesgo o vicio de la cosa, sólo se eximirá total o parcialmente de responsabilidad acreditando la culpa de la víctima o de un tercero por quien no debe responder" (art. $1113,2^{\circ}$. párrafo, Código Civil argentino).

En mérito a la brevedad, remitimos al comentario a dicho precepto en nuestro libro "El artìculo $1113 \mathrm{del}$ Código Civil . Comentado. Anotado", Ed. Hammurabi,Bs.As., Ed. 1983,p. 467 y ss., en colaboración con Roque Garrido.

Desde luego que en todos los casos también podrá eximirse de responsabilidad el productor o dueño o guardián de la cosa, tanto en el derecho argentino, cuanto en el derecho francés, frente a supuestos de caso fortuito o fuerza mayor, toda vez que ello significará la ruptura del nexo de causalidad adecuada.

\section{HECHO DEL TERCERO QUE CONCURRIÓ A LA PRODUCCIÓN DE UN DAÑO}

El artículo 1386-14 del Código Civil francés 'prescribe que "La responsabilidad del productor frente a la víctima no se reduce por el hecho de que un tercero haya concurrido a la realización del daño".

Un antecedente de este artículo podemos encontrarlo en el artículo $5^{\circ}$, apartado $2^{\circ}$. de la Convención de Estrasburgo de 1977 que dice:"La responsabilidad del productor no se reduce cuando el daño ha sido causado 
conjuntamente por un defecto del producto y por la intervención de un tercero".

También debe decirse que de acuerdo a la Directiva de 1985, cuando el daño resultare de manera conjunta de un defecto del producto y de la intervención de un tercero, la responsabilidad de este último estará totalmente sometida al derecho nacional, toda vez que ella no deriva de la Directiva, por lo que la regla de la solidaridad establecida por ésta no se aplicará en este caso.

De este modo, conforme al mencionado artículo 1386-14 del Código Civil francés no habrá reducción de la responsabilidad del productor frente a la víctima por el hecho de que un tercero haya concurrido a la realización del daño.

Aun cuando dicho precepto no lo diga de modo expreso como ocurre en la mencionada Convención de Estrasburgo de 1977 y con la Directiva de 1985 , lo que el mismo quiere significar es que el productor no podrá reducir su responsabilidad cuando el daño fuere causado por el producto defectuoso, aun cuando un tercero haya concurrido a la realización del perjuicio. Y es lógico que ello sea así, por cuanto la concurrencia de este tercero en la producción del daño no podría tener la virtualidad de reducir la responsabilidad que recae sobre el mencionado productor, por cuanto el daño ha sido causado por su producto. Debe quedar bien en claro desde luego que el productor no podrá beneficiarse con reducción alguna de la responsabilidad que le corresponda en tal caso, frente a la vìctima. Ello no impedirá desde luego que dicho productor pueda reclamar a dicho tercero lo que pueda corresponder en razón de la intervención que correspondió al mismo en la producción del evento dañoso.

\section{INEFICACIA DE LAS \\ CLAÚSULAS \\ EXONERATORIAS O \\ LIMITATIVAS DE LA \\ RESPONSABILIDAD POR \\ DAÑOS DERIVADOS DE PRODUCTOS DEFECTUOSOS}

El artículo 1386-15 del Código Civil francés reza: "Las cláusulas que tienden a descartar o a limitar la responsabilidad por el hecho de los productos defectuosos están prohibidas y se reputan como no escritas. No obstante, para los daños causados a los bienes que no son utilizados por las víctimas de modo principal para su uso o consumo privado, las cláusulas estipuladas entre profesionales son válidas".

Dicho texto coincide en líneas generales con el art. 8 de la Convención de Estrasburgo de 1977 y con el art. 12 de la Directiva de 1985.

Nos parece de interés recordar en el presente comentario que el importante anteproyecto de ley de defensa del consumidor preparado oportunamente en nuestro país, por los distinguidos juristas Atilio A. Alterini, Roberto M. López Cabana y Gabriel 
A. Stiglitz propiciaba en su artículo 12 que " se tendrán por no convenidas.... las cláusulas que... limiten la responsabilidad por daños corporales; o la limiten por daños materiales, sin una adecuada equivalencia económica".

En este orden de ideas cabe recordar asimismo que el capítulo IX de la ley argentina de Defensa del Consumidor y del Usuario No. 24240 se titula "De los términos abusivos y cláusulas ineficaces". El mismo comprende los arts. 37 a 39 . En modo especial nos interesa destacar que dicho artículo 37 de la ley prescribe que: "Sin perjuicio de la validez del contrato, se tendrán por no convenidas: a) las cláusulas que desnaturalicen las obligaciones o limiten la responsabilidad por daños; b) las cláusulas que importen renuncia o restricción de los derechos del consumidor o amplíen los derechos de la otra parte; ...".

Comentando el punto recuerdan Gabriel A. y Ruben S. Stiglitz en su conocida obra sobre la materia que la cláusula limitativa de responsabilidad importa una renuncia, antes de verificarse el daño, a los derechos de ejercer una pretensión resarcitoria $o$, con más precisión, una renuncia a un derecho eventual en los términos del art. 872 del Código Civil. Agregan asimismo que tales cláusulas limitativas de responsabilidad quedan descalificadas en razón de que el deudor se beneficia de la impunidad o de una responsabilidad cuyas consecuencias económicas se han limitado convencionalmente. Sobre el particular se sostiene que el deudor no pondría la misma diligencia para ejecutar sus obligaciones que la que debería adoptar sabiéndose responsable. Es por ello que estas cláusulas han sido calificadas como una auténtica invitación a la impericia y a la negligencia (Derechos $y$ defensas del consumidor, Ed. La Rocca, Bs. As.: 1994, p. 261/62).

Cabe recordar que tales cláusulas limitativas de responsabilidad son consideradas como cláusulas abusivas y por ende se tendrán por no convenidas, sin perjuicio de la validez del contrato.

Lo expuesto, aun cuando no se haya mencionado de modo expreso en la ley argentina, resulta de aplicación con mayor razón en el caso de las cláusulas exonerativas de responsabilidad por los daños causados por productos defectuosos. Ello contaba con pacífico sustento de doctrina autoral y jurisprudencial en nuestro país, aun antes del dictado de la ley.

Lo expuesto resulta perfectamente de aplicación en el derecho francés frente a la redacción del mencionado art. 1386-15 que considera prohibidas y por ende como no escritas, las cláusulas que descartaren o limitaren la responsabilidad por el hecho de los productos defectuosos. Con ello se procura defender adecuadamente a los consumidores y usuarios frente a los abusos contractuales que pudieren cometer los profesionales al obligar anticipadamente a aquéllos a limitar o renunciar a sus pretensiones resarcitorias. 
Añádase, que con buen criterio, la parte final del mencionado artículo 1386-15, dispone que no obstante lo dispuesto como regla general en la primera parte del mismo, para los daños causados a los bienes que no fueren utilizados por la víctima de modo principal para su uso o su consumo privado, serán válidas las cláusulas estipuladas entre profesionales.

Es natural que ello sea así por cuanto en este caso, a diferencia del anterior, las relaciones contractuales se entablan entre profesionales, a quienes se supone en un plano de igualdad y de equivalencia de poderío económico, que tornaría innecesario tutela alguna.

Comentando el punto sostienen los Mazeaud y Chabas que dicho texto es el único que en el título IV bis del Código Civil, hace un trato diferenciado distinto a la situación general del consumidor, pues sólo refiere a las relaciones entre profesionales.

De este modo, tales cláusulas exonerativas o limitativas de responsabilidad, solamente seran válidas en las relaciones entre profesionales. Además, tales cláusulas sólo deben referirse a los daños causados a los bienes utilizados a título principalmente profesional (lo que quiere decir por ejemplo que los daños derivados de los productos defectuosos que pudieren tener incidencia en lo que refiere al lucrum cessans, esto es, al perjuicio comercial, no podrán constituir el objeto de cláusulas exoneratorias o limitativas de responsabilidad (Mazeaud y
Chabas,op. cit., Paris, 1998, No. 558-9, p. 647).

\section{DURACIÓN DE LA RESPONSABILIDAD Y PRESCRIPCIÓN}

Dos artículos se ocupan de estas cuestiones. El primero de ellos, es el 1386-16 del Código Civil francés que dice: "Salvo culpa del productor, la responsabilidad de éste, fundada en las disposiciones del presente titulo, se extingue luego de transcurrido diez años posteriores a la puesta en circulación del producto que ha causado el daño, a menos que, durante dicho período, la vìctima hubiere entablado una acción judicial".

El artículo siguiente de dicho cuerpo legal, esto es, el 1386-17 prescribe: "La acción de reparación fundada en las disposiciones del presente título prescribe en una plazo de tres años a contar de la fecha en la cual el actor haya tomado o podido tomar conocimiento del daño, del defecto y de la identidad del productor".

Trataremos separadamente las situaciones contempladas por ambos preceptos. Así tenemos:

1. Conforme lo hemos adelantado en nuestro comentario al art. 1386-12, segundo parte, al que remitimos, en rigor de verdad el artículo 1386-16 contemplaría un supuesto de caducidad de la acción para reclamar por los daños causados, luego de transcurridos diez años a partir de la puesta en 
circulación del producto defectuoso.Pasado dicho lapso se produce la extinción de los derechos de la víctima para efectuar tal clase de reclamos, a menos que durante dicho período hubiere entablado alguna acción judicial. Debemos buscar sus antecedentes inmediatos en la Convención de Estrasburgo de 1977 (art. 7) y en la Directiva de 1985 (art. 11). Ello significa por tanto que si la cosa ocasionara un daño luego de transcurrido màs de diez años a partir del momento de la puesta en circulación de la cosa, el productor no culpable, no responderá. Piensan los Mazeaud y Chabas, que quizás se haya querido tomar en consideración el tiempo de duración media de las cosas muebles en nuestros días. Por lo demàs, luego de transcurridos diez años sería muy difícil probar si el defecto proviene de la vetustez o si el mismo era " congénito" (condición requerida para la responsabilidad de la cosa). A fin de evitar los problemas que pudieren presentarse cabe recordar que el art. 1386-5, in fine, del Código Civil francés, a cuyo comentario remitimos, no puede ser puesto en circulación sino solamente una vez. Asimismo, el productor de la parte componente defectuosa debería ver extinguida su responsabilidad luego de transcurridos diez años a partir de la entrega de dicha parte al fabricante que la transforma o la incorpora en un conjunto, toda vez que la puesta en circulación consiste en su desprendimiento voluntario (Mazeaud y Chabas, op.cit., No. 558-10). Remitimos asimismo a nuestros comentarios a los arts. 1386-6 y 1386-8 de dicho cuerpo legal.

2. El otro supuesto contemplado por el art. 1386-17 se refiere al caso de prescripción de la acción para entablar la correspondiente acción resarcitoria pasado los tres años a partir de la fecha en la cual el actor hubiere sabido o debido saber acerca del daño, el defecto y la identidad del productor. Deben buscarse como antecedentes de la norma al art. 6 de la Convención de Estrasburgo de 1977 y al art. 10 de la Directiva de 1985. Comentando este último precepto - reproducido en forma prácticamente textual por dicho art. 1386-17 - hemos sostenido oportunamente que nos encontramos aquì en presencia de un verdadero plazo de prescripción de tres años a contar desde el momento en que la vìctima ha tenido o podido tener conocimiento acerca del daño causado, del defecto y de la identidad del productor. (cf. nuestro referido trabajo publicado en L.L. 1986-E-947). Resulta asimismo importante tener en cuenta las razones dadas en los fundamentos de la norma también similar de la mencionada Convención de Estrasburgo de 1977, en relación al plazo de prescripción de tres años, cuando se sostuvo que "el comité estimó oportuno establecer tres criterios (conocimiento del daño, del defecto y de la identidad del productor), a fin de prever en el interés de la vìctima, todas las hipótesis posibles. En efecto, frecuentemente, una persona conoce el daño y la identidad del productor pero 
no tiene conciencia del hecho de que el daño deriva de un defecto que se descubre tiempo después que el perjuicio haya sido causado".

Para finalizar recordamos que en el derecho argentino, el plazo de prescripción en el ámbito de la responsabilidad extracontractual es de dos años (art. 4037, C. C.), en tanto que en el ámbito de la responsabilidad contractual es de diez años ( art. 4023).

En cambio, en el Proyecto de Unificación Civil y Comercial de 1987 (hoy ley vetada), con buen criterio, se había propiciado un plazo único de prescripción de cinco años.

\section{VÍCTIMA QUE PUEDE} PREVALERSE DEL DERECHO DE LA RESPONSABILIDAD CONTRACTUAL $O$ EXTRACONTRACTUAL O DE UN RÉGIMEN ESPECIAL DE RESPONSABILIDAD. CULPA DEL PRODUCTOR Y DE SUS DEPENDIENTES

El último artículo del título que estamos comentando, esto es, el art. 1386-18 del Código Civil francés, prescribe que: "Las disposiciones del presente título no implican ataques a los derechos de la víctima de un daño cuando la misma pudiere prevalerse del derecho de la responsabilidad contractual o extracontractual $o \cdot d e$ un régimen especial de responsabilidad. El productor continúa siendo responsable por las consecuencias de su culpa y de las personas por las cuales debe responder".
Podemos encontrar antecedentes de esta disposición en el art. 12 de la Convención de Estrasburgo de 1977 como así también en el art. 13 de la Directiva de 1985.

A la luz de dicho art. 1386-18 podemos decir que su alcance no es otro que el dejar establecido que las pertinentes disposiciones del Código Civil francés incorporadas por la ley $\mathrm{N}^{\circ}$. 98-389 del 19 de mayo de 1998, que acabamos de comentar, no significan en modo alguno privar de la posibilidad que tienen las víctimas de daños derivados de productos defectuosos para acudir al derecho común de la responsabilidad contractual y extracontractual o bien a algún régimen especial de responsabilidad.

En efecto, en determinadas circunstancias puede ser más conveniente y beneficioso para los damnificados acudir al derecho común de la responsabilidad contractual y a la aquiliana. También puede resultarle màs ventajoso acudir a régimenes especiales de responsabilidad, como pudiere ser algún régimen particular que pudiere haberse establecido, por ejemplo, en materia de responsabilidad del productor de medicamentos. En todos los casos se procura por tanto proteger de la mejor manera posible a los damnificados por los daños que pudieren derivarse de productos defectuosos.

El último párrafo contiene una regla que resulta fàcilmente comprensible y que no requiere por tanto de mayores excplicaciones. En efecto, conforme al mismo el productor continuará siendo 
responsable de las consecuencias derivadas de su culpa en la producción del evento dañoso como así de la culpa en que pudieren incurrir las personas que de él dependieren. Ello no es más que la aplicación de principios generales que establecen la responsabilidad del principal por el hecho del dependiente.En general se considera que se trata de una responsabilidad objetiva $o$ sin culpa fundada en el factor de atribución garantía.

Con lo expuesto damos por terminado el presente comentario relativo a los agregados introducidos al Código Civil francés por la ley 98-389 del 19 de mayo de 1998, respecto de la responsabilidad por el hecho de los productos defectuosos, que por cierto deben ser considerados adecuados, en una línea generalmente coincidente con los valiosos precedentes en la materia representados por la Convención de Estrasburgo de 1977 y por la Directiva de 1985 que en cada caso particular nos hemos preocupado de destacar en modo especial. 
